\title{
Normal Vitamin Levels and Nutritional Indices in Alzheimer's Disease Patients with Mild Cognitive Impairment or Dementia with Normal Body Mass Indexes
}

\author{
Ingun Ulstein ${ }^{\mathrm{a}, \mathrm{b}, *}$ and Thomas Bøhmer ${ }^{\mathrm{b}, \mathrm{c}}$ \\ ${ }^{a}$ Department of Old Age Psychiatry, Oslo University Hospital, Ullevaal, Oslo, Norway \\ ${ }^{\mathrm{b}}$ University of Oslo, Faculty of Medicine, Oslo, Norway \\ ${ }^{\mathrm{c}}$ Nutritional Laboratory, Department of Medical Biochemistry, Oslo University Hospital, Aker, Oslo, Norway
}

\begin{abstract}
Evidence supports an association between vitamin deficiencies and cognitive decline in Alzheimer's disease (AD). If vitamin deficiencies are causative for $\mathrm{AD}$ development, they should be detectable during very early stages of $\mathrm{AD}$. Here we investigated nutritional factors among home-living patients diagnosed with mild cognitive impairment (MCI) or mild dementia due to AD, compared to healthy controls. Our study included 73 patients with AD ( 25 with MCI, 48 with dementia) and 63 cognitively intact age-matched controls. All participants underwent cognitive testing, somatic examination, and measurements of vitamins A, B1, B6, folate, B12, C, D, and E, and F2- $\alpha$-isoprostane. Results are given as mean (SD). MMSE scores were 29.1 (1.0) for healthy controls, 27.4 (1.8) for patients with MCI, and 24.3 (3.2) for patients with dementia. Vitamin concentrations for the these groups, respectively, were as follows: B1 (nmol/l), 157 (29), 161 (35), and 161 (32); B6 (nmol/l), 57 (63), 71 (104), and 58 (44); folate (mmol/l), 23 (9), 26 (10), and 23 (11); B12 (pmol/l), 407 (159), 427 (116), and 397 (204); C ( $\mu \mathrm{mol} / \mathrm{l}), 63$ (18), 61 (16), and 63 (29); A ( $\mu \mathrm{mol} / \mathrm{l}), 2.3(0.6), 2.2(0.5)$, and $2.3(0.5)$; $\mathrm{E}(\mu \mathrm{mol} / \mathrm{l}), 36(6.3)$, 36 (6.9), and 36 (8.2); 25-OH vitamin D (nmol/l), 65 (18), 61 (19), and 65 (20); and 8-iso-PGF $\alpha$ (pg/ml), 64 (27); 60 (19), and 66 (51). These concentrations did not significantly differ $(p \leq 0.05)$ between the three groups. Our results do not support the hypothesis that vitamin deficiencies play a causative role in the development of early cognitive impairment.
\end{abstract}

Keywords: Alzheimer's disease, mild cognitive impairment, vitamin deficiencies

\section{INTRODUCTION}

Despite decades of research focused on the etiology of Alzheimer's disease (AD), a major lack of knowledge persists and we do not yet have any effective methods of preventing or curing this condition. The core pathological features of $\mathrm{AD}$ are formation of amyloid plaques and neurofibrillary tangles, with

${ }^{*}$ Correspondence to: Ingun Ulstein, Department of Old Age Psychiatry, Oslo University Hospital, Slottsberget 35, N-1485, Asker, Norway. Tel.: +47 95700025; E-mail: inguls@ous-hf.no. other factors contributing to the degenerative cascade, such as increased oxidative stress, defective mitochondrial function and cellular energy production, and chronic inflammatory mechanisms [1-3]. Genetic studies have also identified several risk genes [4] and protective genes [5], adding to the complexity of $\mathrm{AD}$ etiology.

Prior research has also identified several potentially modifiable risk factors for $\mathrm{AD}$, including a midlife history of hypertension, type 2-diabetes, and obesity [6-8], even in people with apolipoprotein E (APOE) $\varepsilon 4$, a well-established AD risk factor itself 
[9]. These findings support the development of strategies for modifying and preventing $\mathrm{AD}$, including nutritional changes and supplementation based on data suggesting better cognitive performance among non-demented elderly individuals consuming a plantrich diet [10] or fish products [11].

Cognitive decline in AD may be associated with deficits in vitamin uptake and metabolism that lead to reduced protection against peroxidation, followed by possible neuron damage $[12,13]$. A pilot study demonstrated significantly lower concentrations of several vitamins in AD patients with moderatestage dementia, without vascular disease and weight reduction, when compared with healthy age-matched controls [14]. This may imply that modifying nutrition and intake of specific vitamins could protect against brain damage and dementia. In fact, the OPTIMA group in Oxford reported that high-dose supplementation with the vitamins B6, B12, and folic acid slowed brain atrophy in persons with mild cognitive impairment (MCI) [15], particularly in those with high $\omega$-3 fatty acids [16]. If vitamin deficiencies are truly causative for the development of AD dementia, these deficits would be detectable in patients with $\mathrm{MCI}$ or in very early stages of AD dementia.

Our present study aimed to investigate whether micronutrient reductions have a causative relationship to AD. We studied nutrition in healthy control subjects and in patients diagnosed with $\mathrm{AD}$ prior to any substantial weight loss, who did not show any interfering cerebrovascular, neurological, or psychiatric diseases or acute infections that could influence the blood levels of several vitamins [17].

\section{MATERIALS AND METHODS}

This study included 138 participants: 75 patients and 63 healthy controls. Eligible patients were living at home, had sufficient competence to consent, and were referred due to memory problems to the Memory Clinic at Oslo University Hospital, Ullevaal between January 2012 and November 2013. To meet the inclusion criteria, patients had to be suffering from probable AD based on NINCDS-ADRDA criteria [22], fulfill the Winblad criteria for MCI [23] or the ICD-10 criteria for mild dementia, and have a Mini-Mental State Examination (MMSE) score of at least 24/30. Exclusion criteria were frontotemporal dementia, vascular dementia, Lewy body dementia, severe depression, or psychotic features. Two patients were excluded because their follow-up assessments concluded with diagnoses of depressive disorder and Lewy Body dementia, leaving 73 patients in the study. Of the included patients, 25 were diagnosed with MCI, and 48 with dementia.

All patients underwent a comprehensive assessment that included advanced cognitive testing following a standard protocol [18], and MRI scans of the brain with either visual inspection [19] or volumetric hippocampus measurement using Neuroquant software [20, 21]. The MR findings were integrated into the final diagnosis. When appropriate, cerebrospinal fluid was tested for tau protein and amyloid- $\beta$. Diagnoses were discussed in consensus meetings that included experienced geriatricians, psychiatrists, a neurologist, and in some cases a neuropsychologist.

The healthy control group included 63 individuals, of whom 33 were spouses, cohabitants, or siblings of the patients, and the remaining 30 were part of a control cohort previously established for use in brain research and dementia studies. The latter controls were recruited in association with various elective knee, hip, or gynecological operations. All the control subjects were determined to be cognitively intact based on cognitive testing.

At study inclusion, the patients were retested with cognitive tests, such as the Norwegian version of the MMSE [24], Clock-drawing test [25], CERAD 10word test, immediate and delayed memory [26], and Trail-making test A and B [27]. On the day of examination, participant blood samples were collected for standard blood tests, including micro-C-reactive protein (CRP) and vitamin concentrations. We also collected urine samples and, when possible, cerebrospinal fluid for testing dementia markers (these results are not presented in this article). To exclude individuals with cognitive impairment, the control participants were also examined using the same cognitive tests as the patients, and blood and urine samples were collected on the same day.

All participants underwent a clinical assessment that included blood pressure measurement and nutritional status assessment. Weight and height were evaluated, along with upper arm and leg thickness, and body mass index (BMI) was calculated as weight $/$ height $^{2}$. We recorded the units of alcohol consumed per week, and any nicotine use. Participants were asked about their number of daily meals, weekly hot meals, and weekly fish meals, as well as their use of vitamin and nutritional supplements. We recorded any use of antihypertensive medication, statins, or anticoagulants, and relevant cardiovascu- 
lar events. A vascular score was calculated, with one point given for the presence of each of the following: substantial hypertension, coronary heart disease, myocardial infarction, atrial fibrillation, valvular heart disease, precerebral arterial stenosis $>75 \%$, cerebral infarction/bleeding (stroke), later strokes, unilateral paralysis/paresis, unilateral hyperreflexia/spasticity, unilateral inverted plantar reflex, aphasia/dysphasia, dysarthria, dysphagia, epilepsy, and diabetes mellitus. The final score ranged from 0 to 16 , with a tendency to over-diagnose vascular disease.

Initially, we urged the participants who used supplements to stop taking these during the month prior to blood sampling. However, this turned out to be difficult as taking supplements was an established part of the patients' daily routines. Therefore, we instead encouraged participants to not take supplements on the last days before the blood samples were collected.

\section{Biochemical analyses}

Blood samples were collected under standardized conditions and processed by two professional technicians to prevent preanalytic errors. Aliquots were prepared using appropriate additives for the different analytic procedures. Serum aliquots were stored at $-20^{\circ} \mathrm{C}\left(-80^{\circ} \mathrm{C}\right.$ for vitamin $\left.\mathrm{C}\right)$ until analysis. Laboratory analyses were performed within 2 weeks of sample collection at the Nutrition Laboratory, Hormone Laboratory, and Department of Medical Biochemistry, Oslo University Hospital, Aker. Routine laboratory analyses of blood, serum, and plasma were performed using a Hitachi 717 Modular multianalyzer (Boehringer Mannheim, Germany).

The CRP assays had a detection limit $<1 \mathrm{mg} / \mathrm{l}$, calibrated using European Community Bureau of Reference Certified Reference Material 470 (CRM 470). HPLC was used to assess vitamin B-1 (thiamine pyrophosphate in heparinized blood; Chromsystems), vitamin B-6 (pyridoxal-5-phosphate in serum; Chromsystems), vitamin A (retinol in serum; BioRad Laboratories, Munich, Germany), and vitamin $\mathrm{E}$ ( $\alpha$-tocopherol in serum; Bio-Rad Laboratories). Serum samples were analyzed for vitamin C (ascorbic acid) following acidification with ortho-phosphoric acid using the method of Zannoni et al. [28]. Serum was analyzed for 25-hydroxyvitamin D (sum of 25-hydroxyvitamin $\mathrm{D}_{2}$ and 25-hydroxy $\mathrm{D}_{3}$ ) using radioimmunoassay (Dia Sorrin, Stillwater, MN). In our laboratory, these methods showed interassay CVs ranging from 3-9\% based on analysis of $\geq 12$ replicate samples on two different days-except for $25-\mathrm{OH}$ vitamin $\mathrm{D}$, which showed a CV of $14 \%$. Vitamin $\mathrm{C}$ and 25-OH-vitamin D were analyzed in duplicate. All vitamin assays included quality controls with high and low concentrations supplied by the manufacturers, plus internal controls. No external control was available for vitamin C; thus, standards were prepared from the dry substance (SigmaAldrich, St. Louis, MO). Reviewing the quality control results revealed no significant laboratory drift within the study period (January 2012 to November 2013). Liquid chromatography/tandem mass spectrometry was used to analyses $\alpha$-isoprostane [29].

Reference intervals for concentrations of vitamins B-1, B-6, C, A, and E were estimated based on mean concentrations $( \pm 2 \mathrm{SD})$ from a healthy control group in Norway, with separate estimates for men and women. Reference intervals for vitamins with a $\log$ normal distribution were obtained by calculating the mean $(+2 \mathrm{SD})$ of log-transformed values, and back-transforming the result. For 25-hydroxyvitamin $\mathrm{D}$, we used the reference interval from a previously described population [30]. For folic acid, vitamin B-12, hemoglobin, cholesterol, triacylglycerol, and CRP, we used the reference intervals from the Department of Medical Biochemistry, Oslo University Hospital, Aker.

\section{Ethics}

This study was approved by the Regional Committee for Ethics in Medical Research (REK 2011/698) and is registered as Clinical Trial number NCT01479855. Eligible patients and their primary caregivers who were included in this study had previously agreed to join the Norwegian Memory Clinic Registry, and to be contacted about participation in upcoming relevant studies (REK 2009/1953 S08143a). Eligible participants were contacted by telephone and received both oral and written information about the study before they provided written consent to participate. Participants were informed about the possibility of withdrawing their consent if desired.

\section{Statistics}

Statistical analyses were performed using the statistical package SPSS version 21. A chi-square test was used to compare categorical variables, whereas $t$-tests and ANOVA was used to compare normally distributed continuous variables. Descriptive analyses showed a skewed distribution of the 
Table 1

Characteristics of healthy controls and patients with Alzheimer's disease

\begin{tabular}{|c|c|c|c|c|}
\hline & \multirow{2}{*}{$\begin{array}{c}\text { Controls } \\
\mathrm{N}=63\end{array}$} & \multicolumn{2}{|c|}{ Patients } & \multirow[t]{2}{*}{$p$ value } \\
\hline & & $\begin{array}{c}\mathrm{MCI}^{\mathrm{a}} \\
(n=25)\end{array}$ & $\begin{array}{c}\text { Dementia }^{\mathrm{b}} \\
(n=48)\end{array}$ & \\
\hline Females, $n(\%)$ & $38(60.3)$ & $10(40.0)$ & $23(52.1)$ & \\
\hline Males, $n(\%)$ & $25(39.7)$ & $15(60.0)$ & $25(52.1)$ & $0.17^{\mathrm{c}}$ \\
\hline Married, $n(\%)$ & $45(71.4)$ & $20(80.0)$ & $31(64.6)$ & $0.38^{\mathrm{c}}$ \\
\hline Age, mean (SD) & $72.7(6.3)$ & $68.3(6.8)$ & $71.0(8.2)$ & $0.03^{\mathrm{d}}$ \\
\hline Years of schooling, mean $(\mathrm{SD})^{\mathrm{f}}$ & $13.8(3.5)$ & $14.8(3.3)$ & $12.7(3.4)$ & $0.07^{\mathrm{d}}$ \\
\hline Good to very good health condition, $n(\%)^{\mathrm{f}}$ & $40(65.1)$ & $15(54.5)$ & $30(58.8)$ & $0.81^{\mathrm{c}}$ \\
\hline Systolic blood pressure, mean $(\mathrm{SD})^{\mathrm{f}}$ & $153.4(21.6)$ & $141.9(19.1)$ & $149.9(21.7)$ & $0.08^{\mathrm{c}}$ \\
\hline Diastolic blood pressure, mean $(\mathrm{SD})^{\mathrm{f}}$ & $82.5(12.1)$ & $78.1(10.1)$ & $86.9(28.7)$ & $0.12^{\mathrm{e}}$ \\
\hline Vascular score, mean (SD) & $1.1(1.2)$ & $1.0(1.1)$ & $0.8(1.2)$ & $0.41^{\mathrm{e}}$ \\
\hline Weight, mean $(\mathrm{SD})^{\mathrm{f}}$ & $75.0(11.3)$ & $71.2(13.2)$ & $70.7(12.0)$ & $0.15^{\mathrm{d}}$ \\
\hline Height, mean $(\mathrm{SD})^{\mathrm{f}}$ & $170.2(9.1)$ & $172.2(9.2)$ & $172.3(9.1)$ & $0.43^{\mathrm{d}}$ \\
\hline BMI, mean $(\mathrm{SD})^{\mathrm{f}}$ & $25.9(3.5)$ & $23.9(3.4)$ & $23.8(3.4)$ & $0.004^{\mathrm{d}}$ \\
\hline Arm muscle circumference, mean $(\mathrm{SD})^{\mathrm{f}}$ & $28.8(2.9)$ & $28.3(2.8)$ & $27.9(3.3)$ & $0.32^{\mathrm{d}}$ \\
\hline Leg muscle circumference, mean $(\mathrm{SD})^{\mathrm{f}}$ & $37.3(3.4)$ & $40.3(12.4)$ & $36.5(3.6)$ & $0.15^{\mathrm{e}}$ \\
\hline Daily hot meals, $n(\%)^{\mathrm{f}}$ & $51(81.0)$ & $21(84.0)$ & $45(93.4)$ & $0.06^{\mathrm{c}}$ \\
\hline Fish meals $<$ twice per week, $n(\%)^{\mathrm{f}}$ & $12(19.0)$ & $5(20.0)$ & $12(25.0)$ & $0.75^{\mathrm{c}}$ \\
\hline Alcohol units per week, $(\%)^{\mathrm{f}}$ & $5.3(5.5)$ & $3.8(4.5)$ & $2.4(3.6)$ & $0.002^{\mathrm{e}}$ \\
\hline Smokers, $n(\%)^{\mathrm{f}}$ & $8(12.7)$ & $3(12.0)$ & $6(12.5)$ & $0.10^{\mathrm{c}}$ \\
\hline MMSE-NR, mean (SD) & $29.1(1.0)$ & $27.4(1.8)$ & $24.3(3.2)$ & $<0.001^{\mathrm{e}}$ \\
\hline Clock-drawing test, mean (SD) & $4.8(0.6)$ & $4.2(0.9)$ & $3.7(1.3)$ & $<0.001^{\mathrm{e}}$ \\
\hline CERAD-immediate memory, mean (SD) & $20.7(3.9)$ & $17.6(4.8)$ & $12.7(5.2)$ & $<0.001^{\mathrm{d}}$ \\
\hline CERAD-delayed recall, mean $(\mathrm{SD})^{\mathrm{f}}$ & $6.9(1.8)$ & $3.8(2.7)$ & $1.5(1.7)$ & $<0.001^{\mathrm{d}}$ \\
\hline TMTA, mean $(\mathrm{SD})^{\mathrm{f}}$ & $49.8(22.6)$ & $51.9(31.0)$ & $66.8(32.9)$ & $0.004^{\mathrm{e}}$ \\
\hline TMTB, mean $(\mathrm{SD})^{\mathrm{f}}$ & $137.1(91.9)$ & $131.9(64.8)$ & $164.3(81.2)$ & $0.02^{\mathrm{e}}$ \\
\hline
\end{tabular}

Between-group comparisons are made using ANOVA for normally distributed data, and the Kruskal-Wallis H-test for data with a skewed distribution. ${ }^{\mathrm{a}} \mathrm{MCI}$ according to the Winblad criteria; ${ }^{\mathrm{b}}$ Alzheimer's dementia according to the NINCDS-ADRDA criteria; ${ }^{\mathrm{c} P e a r s o n ' s ~ C h i-~}$ square; ${ }^{\mathrm{d}}$ ANOVA; ${ }^{\mathrm{e}}$ Kruskal-Wallis H test; ${ }^{\mathrm{f}}$ Some missing data. SD, Standard division; BMI, Body mass index; MMSE-NR, Mini-Mental Status Examination, Norwegian Revised version; CERAD, Consortium to Establish a Registry for Alzheimer's Disease; TMTA, Trail-Making Test A; TMTB, Trail-Making Test B; n.s., non-significant.

results of cognitive tests and blood tests (except for hemoglobin, hematocrit, cholesterol, and T4); thus, we used the non-parametric Kruskal-Wallis test to compare these data among groups. The study material was divided in three groups: (1) cognitively healthy controls, (2) MCI, and (3) mild dementia due to AD. To explore whether the groups differed with regards to cognitive function, we calculated the discriminatory power between the groups using the Cohen's effect size $(d)$ formula.

\section{RESULTS}

Table 1 reports the participants' demographics and other characteristics, including the cognitive testing results. The majority of both the controls and patients judged their health condition as good to very good. All groups showed a very low vascular score. Antihypertensive medication use was reported by 30 $(41.1 \%)$ patients and $31(49.2 \%)$ controls, whereas as use of statins was reported by 27 (37.0\%) patients and $20(31.7 \%)$ controls, and use of anticoagulants by $22(30.1 \%)$ patients and $17(27.0 \%)$ controls-all non-significant differences. Thirty-two $(43.9 \%)$ of the patients were treated with an acetylcholinesterase inhibitor (AChEI) and one with memantine. Several patients were about to start AChEI treatment as they just had been diagnosed with dementia. Only $4(5.5 \%)$ patients and $5(7.9 \%)$ controls were suffering from diabetes, all except one from type 2 diabetes. BMI was slightly lower among patients with MCI and dementia compared to controls, but the majority of the participants were within a satisfactory weight range except for $2(2.7 \%)$ patients and $1(1.6 \%)$ control with a BMI less than 18.5. Participants in all three groups showed very similar arm and leg circumferences, without sarcopenia. All participants reported a satisfactory number of meals and fish meals, with even those who lived alone having regular daily meals, including dinner, and a fish meal at least 1-2 times a week. Weekly alcohol intake was higher among healthy controls than MCI and dementia patients. Among all participants, only 17 were smokers. Except for lower weight and 
Table 2

Biochemical analyses results among healthy controls and Alzheimer's disease patients with MCI and dementia

\begin{tabular}{|c|c|c|c|c|}
\hline \multirow[t]{3}{*}{ Analysis (normal range) } & \multirow{3}{*}{$\begin{array}{c}\text { Controls } \\
(n=63)\end{array}$} & \multicolumn{2}{|c|}{ Patients } & \multirow[t]{3}{*}{$p$ value } \\
\hline & & $\begin{array}{c}\mathrm{MCI}^{\mathrm{a}} \\
(n=25)\end{array}$ & $\begin{array}{c}\text { Dementia }^{\mathrm{b}} \\
(n=48)\end{array}$ & \\
\hline & & Mean (SD) & Mean (SD) & \\
\hline Hemoglobin $(11.7-15.3 \mathrm{~g} / 100 \mathrm{ml})$ & $13.8(1.2)$ & $14.0(0.9)$ & $14.0(1.2)$ & $0.47^{\mathrm{c}}$ \\
\hline Hematocrit $(0.35-0.46)$ & $0.42(0.03)$ & $0.42(0.02)$ & $0.42(0.03)$ & $0.44^{\mathrm{c}}$ \\
\hline Micro-CRP $(0-4 \mathrm{mg} / \mathrm{l})$ & $3.2(3.1)$ & $1.5(1.2)$ & $1.7(2.3)$ & $0.001^{\mathrm{d}}$ \\
\hline Homocysteine $(5-15 \mu \mathrm{mol} / \mathrm{l})$ & $12.1(4.2)$ & $11.0(2.3)$ & $12.8(4.4)$ & $0.20^{\mathrm{d}}$ \\
\hline Creatinine $(45-90 \mu \mathrm{mol} / \mathrm{l})$ & $73.2(23.1)$ & $75.6(13.2)$ & $80.7(17.1)$ & $0.02^{\mathrm{d}}$ \\
\hline Cholesterol (3.9-7.8 mmol/1) & $5.6(1.2)$ & $5.7(1.0)$ & $6.0(1.2)$ & $0.33^{\mathrm{c}}$ \\
\hline Triglyceride $(0.5-2.6 \mathrm{mmol} / \mathrm{l})$ & $1.4(0.7)$ & $1.2(0.6)$ & $1.3(0.5)$ & $0.13^{\mathrm{d}}$ \\
\hline Thyroxine (T4) (8-21 pmol/l) & $16.4(3.0)$ & $17.1(3.2)$ & $16.5(2.0)$ & $0.58^{\mathrm{c}}$ \\
\hline $\mathrm{TSH}(0.5-3.6 \mathrm{ml} / \mathrm{l})$ & $1.7(0.9)$ & $1.2(0.7)$ & $1.9(2.3)$ & $0.06^{\mathrm{d}}$ \\
\hline
\end{tabular}

Between-group comparisons are made using ANOVA for normally distributed data, and the Kruskal-Wallis H-test for data with a skewed distribution. ${ }^{\mathrm{a}} \mathrm{MCI}$ according to the Winblad criteria; ${ }^{\mathrm{b}}$ Alzheimer's dementia according to the NINCDS-ADRDA criteria; ${ }^{\mathrm{c}}$ ANOVA; ${ }^{\mathrm{d}} \mathrm{Kruskal}-$ Wallis H-test.

Table 3

Vitamin concentrations among healthy controls and Alzheimer's disease patients with MCI and dementia

\begin{tabular}{|c|c|c|c|c|}
\hline \multirow[t]{3}{*}{ Vitamin (normal range) } & \multirow{2}{*}{$\begin{array}{l}\text { Controls } \\
(n=63)\end{array}$} & \multicolumn{2}{|c|}{ Patients } & \multirow[t]{3}{*}{$p$ value } \\
\hline & & $\begin{array}{c}\mathrm{MCI}^{\mathrm{a}} \\
(n=25)\end{array}$ & $\begin{array}{c}\text { Dementia }^{\mathrm{b}} \\
(n=48)\end{array}$ & \\
\hline & Mean (SD) & Mean (SD) & Mean (SD) & \\
\hline Vitamin B1 (Thiamine-diphosphate) $(95-200 \mathrm{nmol} / \mathrm{l})$ & $157.0(28.5)$ & $161.3(35.1)$ & $161.3(31.9)$ & $0.58^{\mathrm{c}}$ \\
\hline Vitamin B6 (Pyridoxal-5 phosphate) $(15-160 \mathrm{nmol} / \mathrm{l})$ & $56.6(63.1)$ & $71.0(104.6)$ & $58.3(44.2)$ & $0.51^{\mathrm{d}}$ \\
\hline Folate $(>10 \mathrm{mmol} / \mathrm{l})$ & $22.7(9.4)$ & $25.7(10.4)$ & $22.9(11.1)$ & $0.74^{\mathrm{c}}$ \\
\hline Vitamin B12 (Cobalamin) (150-650 pmol/1) & $406.5(158.5)$ & $426.5(116.1)$ & $396.5(203.7)$ & $0.21^{\mathrm{d}}$ \\
\hline Vitamin C (Ascorbic acid) $(45-100 \mu \mathrm{mol} / \mathrm{l})$ & $62.8(17.8)$ & $60.6(16.3)$ & $62.8(28.9)$ & $0.87^{\mathrm{c}}$ \\
\hline Vitamin A (Retinol) $(1.2-3.6 \mu \mathrm{mol} / \mathrm{l})$ & $2.3(0.6)$ & $2.2(0.5)$ & $2.3(0.5)$ & $0.39^{\mathrm{c}}$ \\
\hline Vitamin E ( $\alpha$-tocopherol) $(17-45 \mu \mathrm{mol} / \mathrm{l})$ & $35.6(6.3)$ & $35.8(6.9)$ & $36.3(8.2)$ & $0.63^{\mathrm{c}}$ \\
\hline Vitamin D (25-OH Vitamin D) (37-131 nmol/1) & $65.2(17.9)$ & $61.4(18.8)$ & $65.0(20.3)$ & $0.81^{\mathrm{c}}$ \\
\hline 8-iso-PGF $\alpha(30-170 \mathrm{pg} / \mathrm{ml})$ & $64.3(26.8)$ & $59.6(19.3)$ & $65.5(51.1)$ & $0.69^{\mathrm{c}}$ \\
\hline
\end{tabular}

Between-group comparisons are made using ANOVA for normally distributed data, and the Kruskal-Wallis H-test for data with a skewed distribution. ${ }^{\mathrm{a}} \mathrm{MCI}$ according to the Winblad criteria; ${ }^{\mathrm{b}}$ Alzheimer's dementia according to the NINCDS-ADRDA criteria; ${ }^{\mathrm{c}}$ ANOVA; ${ }^{\mathrm{d}}$ KruskalWallis H-test.

height, there were no significant differences between females and males with respect to other background characteristics. However, the percentage of females was lower among the patients than in a general AD population.

Cognitive testing (except Trail-making test B; TMTB) revealed significant differences between the three groups: healthy controls, patients with MCI, and patients with dementia (Table 1).

We calculated Cohen's $d$ (effect size) of the cognitive testing results to discriminate between the MCI and dementia patients, finding $d$ values of 0.98 for the MMSE, 0.50 for the Clock-Drawing Test, 0.89 CERAD immediate memory, 0.98 for CERAD delayed recall, and 0.45 for TMTA. A $d$ of 0.5 or higher is usually of clinical interest, and a value above 0.8 is considered to be high [31]. These results supported dividing the patient material into two groups: MCI and dementia patients, which were both dif- ferent from the controls. The $d$ for TMTB was not calculated as several of the patients did not manage to complete the test.

Routine biochemical analyses revealed satisfactory concentrations for most parameters among all participants. There were no significant betweengroup differences except for mean micro-CRP (Table 2), which was higher among healthy controls that among patients, but was within the inclusion criteria for both groups and was thus assumed to not influence the vitamin concentrations. There were also some significant differences in the routine blood analyses between females and males, but all values were within the normal range.

The blood concentrations of vitamins B-1, B-6, folic acid, B-12, C, A, E, D and of the peroxidative indicator 8-iso-PGF $\alpha$ all fell within the normal range, and did not differ between controls, MCI patients, and dementia patients (Table 3). Males had significant 
Table 4

Overview of vitamin and supplement intake during the last month among healthy controls and Alzheimer's disease patients with MCI and dementia

\begin{tabular}{|c|c|c|c|c|}
\hline & \multirow[b]{2}{*}{$\begin{array}{c}\text { All } \\
(n=136) \\
n(\%)\end{array}$} & \multirow[b]{2}{*}{$\begin{array}{c}\text { Controls } \\
(n=63) \\
n(\%)\end{array}$} & \multicolumn{2}{|c|}{ Patients } \\
\hline & & & $\begin{array}{c}\mathrm{MCI}^{\mathrm{a}} \\
(n=25) \\
n(\%)\end{array}$ & $\begin{array}{c}\mathrm{AD}^{\mathrm{b}} \\
(n=48) \\
n(\%)\end{array}$ \\
\hline Any vitamins in the last month, $n(\%)$ & $83(61.0)$ & $39(61.9)$ & $20(80.0)$ & $24(50.0)$ \\
\hline Vitamins on the day of blood sampling, $n(\%)$ & $13(9.6)$ & $4(6.3)$ & $5(20.0)$ & $4(8.3)$ \\
\hline Multivitamins, $n(\%)$ & $33(24.3)$ & $19(30.2)$ & $7(28.0)$ & $7(14.6)$ \\
\hline Vitamin A, $n(\%)$ & 0 & 0 & 0 & 0 \\
\hline Vitamin B (1 and 6), $n(\%)$ & $13(9.6)$ & $7(11.1)$ & $2(8.0)$ & $4(8.3)$ \\
\hline Vitamin B12, $n(\%)$ & $3(2.2)$ & $1(1.6)$ & 0 & $2(4.2)$ \\
\hline Folic Acid, $n(\%)$ & $2(1.5)$ & $1(1.6)$ & 0 & $1(2.1)$ \\
\hline TrioBe, $n(\%)$ & $9(6.6)$ & $2(3.2)$ & $4(16.0)$ & $3(6.3)$ \\
\hline Vitamin C, $n(\%)$ & $19(14.0)$ & $9(14.3)$ & $1(4.0)$ & $9(18.8)$ \\
\hline Vitamin $\mathrm{D}, n(\%)$ & $12(8.8)$ & $3(4.8)$ & $3(12.0)$ & $6(12.5)$ \\
\hline Vitamin E, $n(\%)$ & $1(0.7)$ & 0 & 0 & $1(2.1)$ \\
\hline Calcium, $n(\%)$ & $10(7.4)$ & $4(6.3)$ & $4(16.0)$ & $2(4.2)$ \\
\hline Omega- 3 or Fish oil, $n(\%)$ & $61(44.9)$ & $30(47.6)$ & $14(56.0)$ & $17(35.4)$ \\
\hline Other supplements, $n(\%)$ & $27(19.9)$ & $10(15.9)$ & $7(28.0)$ & $10(20.8)$ \\
\hline
\end{tabular}

${ }^{\mathrm{a}} \mathrm{MCI}$ according to the Winblad criteria; ${ }^{\mathrm{b}}$ Alzheimer's dementia according to the NINCDS-ADRDA criteria.

lower concentrations of folate, vitamin B12, C, and $\mathrm{E}$ than females, but still within the normal range (not shown).

Among all participants, 83 (61\%) had used some kind of supplement prior to blood sampling (Table 4). We found significant differences in vitamin concentrations between those using and not using vitamin supplementation (not shown), however the values were all within the normal range in both groups The majority of participants who took any kind of vitamin or micronutrient were regular users of multivitamins or fish oil and omega-3 fatty acids.

\section{DISCUSSION}

The main finding of our present study was that mean vitamin levels were within normal ranges among both the cognitively intact control subjects and the AD patients with MCI and mild dementia. Moreover, these vitamin concentrations did not significantly differ among the three groups. Thus, our results did not substantiate the hypotheses that vitamin deficits could be causative for AD. Our findings are supported by earlier reviews [32-34] showing that vitamin supplementation had no certain beneficial effects with regards to $\mathrm{AD}$ prevention or improvement of cognition. However, our findings are in contrast to the results of a meta-analysis by da Silva et al. [35], which included 80 studies performed from 1990-2012, and reported significantly lower plasma levels of folate and vitamins A, B12,
$\mathrm{C}$, and $\mathrm{E}$ among dementia patients, and Olde Rikkert et al. [36] who compared cognitively healthy controls with non-malnourished patients with mild AD, and found small differences in nutrient uptake among the AD patients.

The satisfactory vitamin concentrations found in our patients with normal BMI values and stable weight over time, were likely attained either from following normal nutritional patterns with daily hot meals and regular fish meals, or from regular use of vitamins and supplements, especially fish oil, which was introduced in early childhood for many, in contrast to Shartenstein et al. [37] who in their oneyear follow-up study, found suboptimal diets among patients with early dementia compared to in cognitively healthy age-matched controls. Low vitamin concentrations may thus occur as a consequence of changes in dietary patterns towards unhealthy compositions of food intake, especially in more advanced dementia [38].

Our results may have also been influenced by the fact that vitamin levels-including B12 and folate and, in the later years, vitamin D-are controlled and supplemented as part of the routine assessment and follow-up of older people in Norway. Thus, our findings cannot exclude the possibility that targeted vitamin supplementation can act as a modifying measure [39], although it is less likely that vitamin intake can prevent dementia onset. However, the unfavorable results in some intervention studies could be due to supplementation with only a few of the many involved nutrients, insufficient dosages, 
or supplementation too late in the disease course as $\mathrm{AD}$ has a long latency period, slow progression, and vague symptoms during its very early preclinical stages, making it difficult to determine appropriate timing for vitamin supplementation before substantial brain damage has occurred. Reduced brain atrophy in MCI patients who received high-dose supplementation with vitamins B6, B12, and folate-especially among patients showing high concentrations of long-chain $\omega-3$ fatty acids found by the OPTIMA group [16] is promising [40]. There is also some evidence of cognitive improvement in MCI patients with high homocysteine levels who received high-dose supplementation with vitamin B [41]. However, these findings are not yet sufficient to guide specific dietary advice, they are in line with other findings suggesting that modifying risk factors of cognitive decline may improve cognition or even delay dementia development [9].

Supplements are generally considered to be safe, with no substantial side-effects, socially acceptable, and cost effective [42]. Supplementation with vitamins $\mathrm{C}$ and $\mathrm{E}$ are assumed to be beneficial due to their antioxidative effects [43]. However, a Cochrane review from 2012 [44] concluded that the application of such treatment in controlled randomized studies has not shown convincing benefits and is in line with our findings showing no association between vitamins and cognition. Supplements can also be costly, may have no effect, and can reduce motivation to adopt a healthier lifestyle [34]. Some recent studies have even showed increased cognitive dysfunction in patients who received high-dose supplementation with vitamins A, E, and C [45, 46]. Since those of our patients taking supplements regularly had normal vitamin concentrations, they probably were not overusing these vitamins.

The patients in our study showed generally low vascular scores (mean values from 0.8-1.1) of a maximal score of 16), with hypertension, atrial fibrillation und use of anticoagulants being the main reasons for scores above zero. Both hypertension and atrial fibrillation are considered important risk factors for developing dementia or $\mathrm{AD}[6,8]$ together with hypercholesterolemia. However, both control participants and patients in this study were taking appropriate medication that seemed to control these symptoms. In fact, hypertension was more frequent among the cognitively intact controls than the AD patients, suggesting that other risk factors were more important.

The findings of an earlier study concluded that vitamin deficits were a possible cause of AD [14] were likely associated with external factors, such as acute infections or operations that may influence the vitamin concentrations, especially lipid-soluble vitamins [17]. Thus, it is important to consider the conditions under which blood samples are collected. In particular, inflammatory states with increasing CRP can reduce the usefulness of vitamin measurements [47]. Our present results showed very low CRP levels in both patients and controls (Table 2), supporting the use of serum vitamin concentrations as valid expressions for vitamin nutritional status. Other factors, such as secondary nutritional deficiencies that can develop during disease progression, must also be considered when studying the association between vitamins and cognition [34].

Among the AD patients in our study, $80 \%$ of MCI patients and $50 \%$ of dementia patients regularly took nutritional supplements without compelling influence on their cognitive function. For the majority of patients, their supplement use was based on what they were accustomed to taking, and not due to any documented deficiency—although a few patients received vitamin supplementation because of low B12 and vitamin D. It remains unknown whether customized vitamin supplementation in people with reduced vitamin levels will have a long-term influence on cognition. Other known risk factors for $\mathrm{AD}$ - such as a low education level, hypercholesterolemia, high homocysteine level, and diabetes-were rare among the patients in this study. Thus, this patient population might be useful for testing new and previous unknown factors that could be causal for AD development.

\section{Strengths and limitations}

The included patients were all recruited from the same memory clinic and underwent a comprehensive standardized assessment. The demographic characteristics, somatic health conditions, and general nutritional indices were rather similar among the three groups, which were clearly discriminated by the results of cognitive testing.

One obvious limitation of this study was the use of different kinds of supplements, which could have influenced the results. Participants were asked to not take supplements on the last days before blood sampling, but could not verify to what an extent this request was followed, except by asking the participants. Another limitation was the cross-sectional design. A longitudinal follow-up could have added greater weight to our results. Our patient sample was 
also somewhat younger than a normal AD population. They were relatively physically fit with few comorbid illnesses. Thus, we cannot necessarily generalize our findings to the global population of AD patients, even though our results convincingly demonstrate a lack of association between impaired cognition and micro-nutrients.

\section{Conclusion}

Our present results showed no associations between vitamin concentrations and early cognitive impairment in patients suffering from AD. The normal blood concentrations, nutritional indices, and food intake observed in our patients did not support the hypothesis that vitamin deficiencies are causative for AD development.

\section{ACKNOWLEDGMENTS}

We express our gratitude to all of the patients and spouses who participated in or supported this study. Our study was supported by a grant from Health South-East (no. 2005199). The bioengineers Kjersti Vesterheim and Theresa May prepared the different blood, urine, and spinal fluid samples from the Memory Clinic. Øystein Bergøy helped with recruitment and performed cognitive testing of the additional control participants. Merete Berge Pettersen and Anne B. Hove of the Nutritional Laboratory performed the nutritional analyses. Nasser Bastani of the Nutritional Institute, University of Oslo, performed the F2-isoprostane analyses. The routine chemical analyses were performed at the Department of Med Biochemistry, Aker University Hospital.

Authors' disclosures available online (http://j-alz. com/manuscript-disclosures/16-0393r1).

\section{REFERENCES}

[1] Cunnane S, Nugent S, Roy M, Courchesne-Loyer A, Croteau E, Tremblay S, Castellano A, Pifferi F, Bocti C, Paquet N (2011) Brain fuel metabolism, aging, and Alzheimer's disease. Nutrition 27, 3-20.

[2] Rubio-Perez JM, Morillas-Ruiz JM (2012) A review: Inflammatory process in Alzheimer's disease, role of cytokines. ScientificWorldJournal 2012, 756357.

[3] Rao AV, Balachandran B (2002) Role of oxidative stress and antioxidants in neurodegenerative diseases. Nutr Neurosci 5, 291-309.

[4] Chouraki V, Seshadri S (2014) Genetics of Alzheimer's disease. Adv Genet 87, 245-294.

[5] Jonsson T, Atwal JK, Steinberg S, Snaedal J, Jonsson PV, Bjornsson S, Stefansson H, Sulem P, Gudbjartsson
D, Maloney J (2012) A mutation in APP protects against Alzheimer's disease and age-related cognitive decline. Nature 488, 96-99.

[6] Kivipelto M, Ngandu T, Laatikainen T, Winblad B, Soininen $\mathrm{H}$, Tuomilehto $\mathrm{J}$ (2006) Risk score for the prediction of dementia risk in 20 years among middle aged people: A longitudinal, population-based study. Lancet Neurol 5, 735-741.

[7] Daviglus ML, Plassman BL, Pirzada A, Bell CC, Bowen PE, Burke JR, Connolly ES Jr, Dunbar-Jacob JM, Granieri EC, McGarry K, Patel D, Trevisan M, Williams JW Jr (2011) Risk factors and preventive interventions for Alzheimer disease: State of the science. Arch Neurol 68, 1185-1190.

[8] Imtiaz B, Tolppanen A-M, Kivipelto M, Soininen H (2014) Future directions in Alzheimer's disease from risk factors to prevention. Biochem Pharmacol 88, 661-670.

[9] Strand BH, Rosness TA, Engedal K, Magnus P, Bergem ALM, Schirmer H, Bjertness E, Knudsen GP (2015) Interaction of apolipoprotein $\mathrm{E}$ genotypes, lifestyle factors and future risk of dementia-related mortality: The Cohort of Norway (CONOR). Dement Geriatr Cogn Disord 40, 137147.

[10] Nurk E, Refsum H, Drevon CA, Tell GS, Nygaard HA, Engedal K, Smith AD (2010) Cognitive performance among the elderly in relation to the intake of plant foods. The Hordaland Health Study. Br J Nutr 104, 1190-1201.

[11] Nurk E, Drevon CA, Refsum H, Solvoll K, Vollset SE, Nygård O, Nygaard HA, Engedal K, Tell GS, Smith AD (2007) Cognitive performance among the elderly and dietary fish intake: The Hordaland Health Study. Am J Clin Nutr 86, 1470-1478.

[12] Bourdel Marchasson I, Delmas Beauvieux MC, Peuchant E, Richard Harston S, Decamps A, Reignier B, Emeriau JP, Rainfray M (2001) Antioxidant defences and oxidative stress markers in erythrocytes and plasma from normally nourished elderly Alzheimer patients. Age Ageing 30, 235241.

[13] Harrison FE (2012) A critical review of vitamin C for the prevention of age-related cognitive decline and Alzheimer's disease. J Alzheimers Dis 29, 711-726.

[14] Glasø M, Nordbø G, Diep L, Bøhmer T (2003) Reduced concentrations of several vitamins in normal weight patients with late-onset dementia of the Alzheimer type without vascular disease. J Nutr Health Aging 8, 407-413.

[15] Smith AD, Smith SM, De Jager CA, Whitbread P, Johnston C, Agacinski G, Oulhaj A, Bradley KM, Jacoby R, Refsum H (2010) Homocysteine-lowering by B vitamins slows the rate of accelerated brain atrophy in mild cognitive impairment: A randomized controlled trial. PloS One 5, e12244.

[16] Jernerén F, Elshorbagy AK, Oulhaj A, Smith SM, Refsum H, Smith AD (2015) Brain atrophy in cognitively impaired elderly: The importance of long-chain $\omega$-3 fatty acids and $\mathrm{B}$ vitamin status in a randomized controlled trial. Am J Clin Nutr 102, 215-221.

[17] Gray A, McMillan DC, Wilson C, Williamson C, O'Reilly DSJ, Talwar D (2005) The relationship between the acute changes in the systemic inflammatory response, lipid soluble antioxidant vitamins and lipid peroxidation following elective knee arthroplasty. Clin Nutr 24, 746-750.

[18] Brækhus A, Ulstein I, Wyller T, Engedal K (2011) The Memory Clinic-Outpatient assessment when dementia is suspected. Tidsskr Nor Legeforen 22, 2254-2257.

[19] Scheltens P, Leys D, Barkhof F, Huglo D, Weinstein H, Vermersch P, Kuiper M, Steinling M, Wolters EC, Valk 
J (1992) Atrophy of medial temporal lobes on MRI in "probable" Alzheimer's disease and normal ageing: Diagnostic value and neuropsychological correlates. J Neurol Neurosurg Psychiatry 55, 967-972.

[20] Brewer JB, Magda S, Airriess C, Smith ME (2009) Fullyautomated quantification of regional brain volumes for improved detection of focal atrophy in Alzheimer disease. AJNR Am J Neuroradiol 30, 578-580.

[21] Engedal K, Brækhus A, Andreassen OA, Nakstad PH (2012) Diagnosis of dementia-automatic quantification of brain structures. Tidsskr Nor Laegeforen 132, 1747-1751.

[22] McKhann G, Drachman D, Folstein M, Katzman R, Price D, Stadlan EM (1984) Clinical diagnosis of Alzheimer's disease: Report of the NINCDS-ADRDA Work Group under the auspices of department of health and human services task force on Alzheimer's disease. Neurology 34, 939-944.

[23] Winblad B, Palmer K, Kivipelto M, Jelic V, Fratiglioni L, Wahlund LO, Nordberg A, Bäckman L, Albert M, Almkvist O, Arai H, Basun H, Blennow K, de Leon M, DeCarli C, Erkinjuntti T, Giacobini E, Graff C, Hardy J, Jack C, Jorm A, Ritchie K, van Duijn C, Visser P, Petersen RC (2004) Mild cognitive impairment-beyond controversies, towards a consensus: Report of the International Working Group on Mild Cognitive Impairment. J Intern Med 256, 240-246.

[24] Folstein MF, Folstein SE, McHugh PR (1975) "Mini-mental state": A practical method for grading the cognitive state of patients for the clinician. J Psychiatr Res 12, 189-198.

[25] Shulman KI, Pushkar Gold D, Cohen CA, Zucchero CA (1993) Clock drawing and dementia in the community: A longitudinal study. Int J Geriatr Psychiatry 8, 487-496.

[26] Morris JC, Mohs R, Rogers H, Fillenbaum G, Heyman A (1989) Consortium to establish a registry for Alzheimer's disease (CERAD) clinical and neuropsychological assessment of Alzheimer's disease. Psychopharmacol Bull 24, 641-652.

[27] Reitan R, Wolfson D (1985) The Halstead-Reitan Neuropsychological Test Battery, Neuropsychology Press, Tucson, AZ.

[28] Zannoni V, Lynch M, Goldstein S, Sato P (1974) A rapid micromethod for the determination of ascorbic acid in plasma and tissues. Biochem Med 11, 41-48.

[29] Bastani NE, Gundersen TE, Blomhoff R (2009) Determination of 8 -epi $\mathrm{PGF}_{2 \alpha}$ concentrations as a biomarker of oxidative stress using triple-stage liquid chromatography/tandem mass spectrometry. Rapid Commun Mass Spectrom 23, 2885-2890.

[30] Meyer C (2004) Scientists probe role of vitamin D: Deficiency a significant problem, experts say. JAMA 292, 1416-1418.

[31] Larner AJ (2014) Effect size (Cohen's d) of cognitive screening instruments examined in pragmatic diagnostic accuracy studies. Dement Geriatr Cogn Disord 3, 236-241.

[32] Malouf R, Areosa Sastre A (2003) Vitamin B12 for cognition. Cochrane Database Syst Rev 3, CD004326.

[33] Malouf R, Grimley Evans J (2003) The effect of vitamin B6 on cognition. Cochrane Database Syst Rev 4, CD004393.

[34] Cooper JK (2014) Nutrition and the brain: What advice should we give? Neurobiol Aging 35, S79-S83.
[35] da Silva SL, Vellas B, Elemans S, Luchsinger J, Kamphuis P, Yaffe K, Sijben J, Groenendijk M, Stijnen T (2014) Plasma nutrient status of patients with Alzheimer's disease: Systematic review and meta-analysis. Alzheimers Dement 10, 485-502.

[36] Olde Rikkert MG, Verhey FR, Sijben JW, Bouwman FH, Dautzenberg PL, Lansink M, Sipers WM, van Asselt DZ, van Hees AM, Stevens M, Vellas B, Scheltens P (2014) Differences in nutritional status between very mild Alzheimer's disease patients and healthy controls. J Alzheimers Dis 41, 261-271.

[37] Shatenstein B, Kergoat MJ, Reid I (2007) Poor nutrient intakes during 1-year follow-up with community-dwelling older adults with early-stage Alzheimer dementia compared to cognitively intact matched controls. J Am Diet Assoc 107, 2091-2099.

[38] Marino LV, Ramos LF, Chiarello PG (2015) Nutritional status according to the stages of Alzheimer's disease. Aging Clin Exp Res 27, 507-513.

[39] Gillette-Guyonnet S, Secher M, Vellas B (2013) Nutrition and neurodegeneration: Epidemiological evidence and challenges for future research. Br J Clin Pharmacol 75, 738-755.

[40] Eriksdotter M, Vedin I, Falahati F, Freund-Levi Y, Hjorth E, Faxen-Irving G, Wahlund L-O, Schultzberg M, Basun H, Cederholm T, Palmblad J (2015) Plasma fatty acid profiles in relation to cognition and gender in Alzheimer's disease patients during oral omega-3 fatty acid supplementation: The OmegAD Study. J Alzheimers Dis 48, 805-812.

[41] de Jager CA, Oulhaj A, Jacoby R, Refsum H, Smith AD (2012) Cognitive and clinical outcomes of homocysteinelowering B-vitamin treatment in mild cognitive impairment: A randomized controlled trial. Int J Geriatr Psychiatry 27, 592-600.

[42] Swaminathan A, Jicha GA (2014) Nutrition and prevention of Alzheimer's dementia. Front Aging Neurosci 6, 282.

[43] Rinaldi P, Polidori MC, Metastasio A, Mariani E, Mattioli P, Cherubini A, Catani M, Cecchetti R, Senin U, Mecocci P (2003) Plasma antioxidants are similarly depleted in mild cognitive impairment and in Alzheimer's disease. Neurobiol Aging 24, 915-919.

[44] Farina N, Isaac M, Clark AR, Rusted J, Tabet N (2012) Vitamin E for Alzheimer's dementia and mild cognitive impairment. Cochrane Database Syst Rev 11, CD002854.

[45] Lloret A, Badía M-C, Mora NJ, Pallardó FV, Alonso M-D, Viña J (2009) Vitamin E paradox in Alzheimer's disease: It does not prevent loss of cognition and may even be detrimental. J Alzheimers Dis 17, 143-149.

[46] Galasko DR, Peskind E, Clark CM, Quinn JF, Ringman JM, Jicha GA, Cotman C, Cottrell B, Montine TJ, Thomas RG, Aisen P (2012) Antioxidants for Alzheimer disease: A randomized clinical trial with cerebrospinal fluid biomarker measures. Arch Neurol 69, 836-841.

[47] Duncan A, Talwar D, McMillan DC, Stefanowicz F, O'Reilly DS (2012) Quantitative data on the magnitude of the systemic inflammatory response and its effect on micronutrient status based on plasma measurements. Am J Clin Nutr 95, 64-71. 